Jurnal Keperawatan Padjadjaran

ISSN 2338-5324 (print)

ISSN 2442-7276 (online)

Online di http://jkp.fkep.unpad.ac.id

DOI : $10.24198 / \mathrm{jkp}$

\title{
Prone Position Improve Physiological Parameters of Preterm Infants Weaning from CPAP: A Randomized Control Trial
}

\author{
Ayu Simorangkir ${ }^{1}$, Yeni Rustina ${ }^{2}$, Defi Efendi ${ }^{3}$ \\ ${ }^{1,2}$ Faculty of Nursing, Universitas Indonesia, Depok, Indonesia, \\ ${ }^{3}$ Neonatal Intensive Care Unit, RSUI, Depok, Indonesia \\ Corresponding Email: simorangkir.ayu@gmail.com
}

Received: 29-01-2021 Revised: 23-04-2021 Accepted: 28-04-2021

\begin{abstract}
The need for continuous positive airway pressure (CPAP) was vital for preterm infant with respiratory distress, but the impact of long-term use was very harmful. The effort to do weaning must be done and facilitate the infant to adapt wean off CPAP. The effect of positioning on stabilized physiological parameters may help preterm infant to adapt under gradual weaning from CPAP. Aim in this study to determine the effect of prone positioning on physiological parameters in preterm infants under gradual weaning CPAP. From Mei to September 2020 total sample 60 preterm infants on non-invasive ventilation or CPAP were randomized into prone position (intervention group, $\mathrm{n}=30$ ) and supine position (control group, $\mathrm{n}=30$ ). Oxygen saturation, respiratory and heart rate between groups were compared. In the prone position was significant higher than supine position at 30th minute. The mean oxygen saturation in the prone position $(99.87 \pm 0.35)$ was higher than in the supine position $(97.63 \pm 1.45$; $\mathrm{p}=0.001)$, the mean respiratory rate in the prone position $(42.10 \pm 8.59$ breaths $/ \mathrm{min})$ was lower than in the supine position $(53.20 \pm 6.24$ breaths/min; $\mathrm{p}=0.001)$, and the mean heart rate in the prone position $(144.63 \pm 13.07 /$ beats $/ \mathrm{min})$ was lower than in the supine position $(153.53 \pm 10.02 /$ beats $/ \mathrm{min} ; \mathrm{p}=0.001)$, so that the prone position can be applied to increase oxygen saturation and to maintain the stability of respiratory rate in preterm infants during gradual weaning. The failure to wean off CPAP (re-CPAP) in the prone group was less frequent which is 3 respondents $(5 \%$ versus $10 \%)$. However, there is no relation between positioning and re-CPAP $(p=0.472)$.
\end{abstract}

Keywords: Preterm infant, prone position, weaning CPAP. 


\section{Introduction}

Generally, premature infants have respiratory distress syndrome (RDS). This occurs in newborns less than 28 weeks' gestation and is very rare in full-term babies (Torabian, Alinejad, Bayati, Rafiei, \& Khosravi, 2019). RDS was more common in premature babies because the lungs of premature babies were not able to produce sufficient surfactant, making it difficult for the lungs to expand, and requiring more energy to breathe (Montgomery, Choy, Steele, \& Hough, 2014). Clinical manifestations that arise from respiratory distress syndrome, namely increased respiratory rate, decreased saturation, cyanosis, and decreased pulmonary sound (Emaliyawati, Fatimah, \& Lidya, 2018). Newborns with prematurity, difficulty breathing or respiratory distress must admitted immediately in the neonatal intensive care unit (NICU) (Hendrawati et al., 2017).

Respiratory distress syndrome in preterm infants can be treated with non-invasive ventilator such as continuous positive airway pressure (CPAP) (Ho, Subramaniam, \& Davis, 2020). CPAP is widely used in NICU in some major hospitals in Indonesia. Based on the medical record data of the Perinatology Unit of the Department of Pediatrics, Cipto Mangunkusumo Hospital (IKA RSCM), 180 (24\%) babies receive CPAP. In addition, the medical record data of Fatmawati Central General Hospital, from January to June 2020, found that 187 babies received intensive care and $54(28.9 \%)$ babies received CPAP therapy. Meanwhile, the number of babies who received intensive care at the Gatot Subroto Army Hospital, from January to June 2020, $66(18.6 \%)$ babies received CPAP therapy.

Currently, the early initial use of continuous positive airway pressure give potential benefits rather than mechanical ventilation (Dunn et al., 2011). This has led practice guidelines and recommendation by the American Academy of Pediatrics (AAP) to utilize CPAP as the primary mode of respiratory support even the most premature infants (Committee on Fetus and Newborn, 2014). There were several adverse side effect in long-term useing CPAP, namely nose damage, delay in oral feeding, prolonged hospitalization, decreased parental ties, and developmental therapy (Lam et al., 2019). The CPAP weaning process must be done when the respiratory stability criteria are met (Abdel-Hady, Shouman, \& Nasef, 2015). The criteria for readiness for weaning from nasal CPAP for 24-48 hour before weaning were the pressure at $\mathrm{FiO} 2$ of 0.21 , normal work of breathing with no persistent tachypnea (60 breaths for $>2 \mathrm{~h}$ ), Oxygen saturation $>93 \%$, no apnea associated with bradycardia (heart rate $<100$ beats/minute) (Amatya et al., 2014; Chawla et al., 2017).

The success of wean off CPAP is based on the individual's ability to adapt to spontaneous breathing and maintain adequate gas exchange (Lam et al., 2019). The proper weaning process in premature babies from wean off CPAP in a stable condition was very useful for reducing complications (Maffei, Gorgoglione, \& Vento, 2017). The weaning process was too fast reported, it would increase the frequency of apnea, air leakage syndrome, abdominal distension, increasing work of breathing, and oxygen demand which results in babies returning to use mechanical ventilation (Abdel-Hady et al., 2015).

The positioning in premature infants was the basic standard of neonatal nursing. A prior study (Malagoli et al., 2012) found that prone position was associated with decreased inspiratory pressure and increased oxygen saturation compared to the supine position in preterm infants during the weaning process from mechanical ventilation. Few studies about the impacts of positioning preterm infant on their adaptation to spontaneous respiration after weaning from mechanical ventilation (Güler \& Çalışır, 2020). Moreover, various studies have pointed to the effects of prone positioning while they under continuous positive airway pressure (CPAP) were oxygen saturation more stable, lower respiration rate, heart rate more stable, also improving ventilation and optimizing gas exchange (Babaei et al., 2019; Ghorbani, Asadollahi, \& Valizadeh, 2013). However, the author was not found the study about the effect of body positioning during weaned off CPAP and lack of trial evaluating position to prevent CPAP failure. The critical conditions that need to continue is observed when premature babies under weaning of the CPAP. 
The evaluation was related to the impact of body positioning on oxygenation status namely oxygen saturation, heart rate, and respiratory rate. The purpose of this study was to identify the impact of the prone and supine position on oxygen saturation, heart rate, and respiratory rate in preterm infants undergoing the CPAP weaning process.

\section{Method}

This study used a parallel-group study design with a randomized controlled trial (RCT). This study follows the guidelines of the Consolidated Standards of Reporting Trials (CONSORT). The intervention group was the prone position setting intervention group and the control group was the supine position. The sample in this study were all preterm infants with respiratory distress who underwent gradual weaning with a decrease in oxygen fraction $<25 \%$ (Dargaville et al., 2013). The study was conducted from May to September 2020 in the Neonatal Intensive Care Unit (NICU), Fatmawati Hospital and Gatot Subroto Army Hospital, Jakarta. Block randomization technique using computerized was used. After obtaining consent from infants' parents, the author provide initial randomization results on in envelopes. Then the nurse took the envelope according to the order of the baby, the mother of the premature infant had no knowledge of which treatment was given in the room.

Premature infants receiving care in the NICU were recruited if they met the following criteria: 1) aged $<37$ weeks based on the Ballard score; 2) diagnosed with RDS and

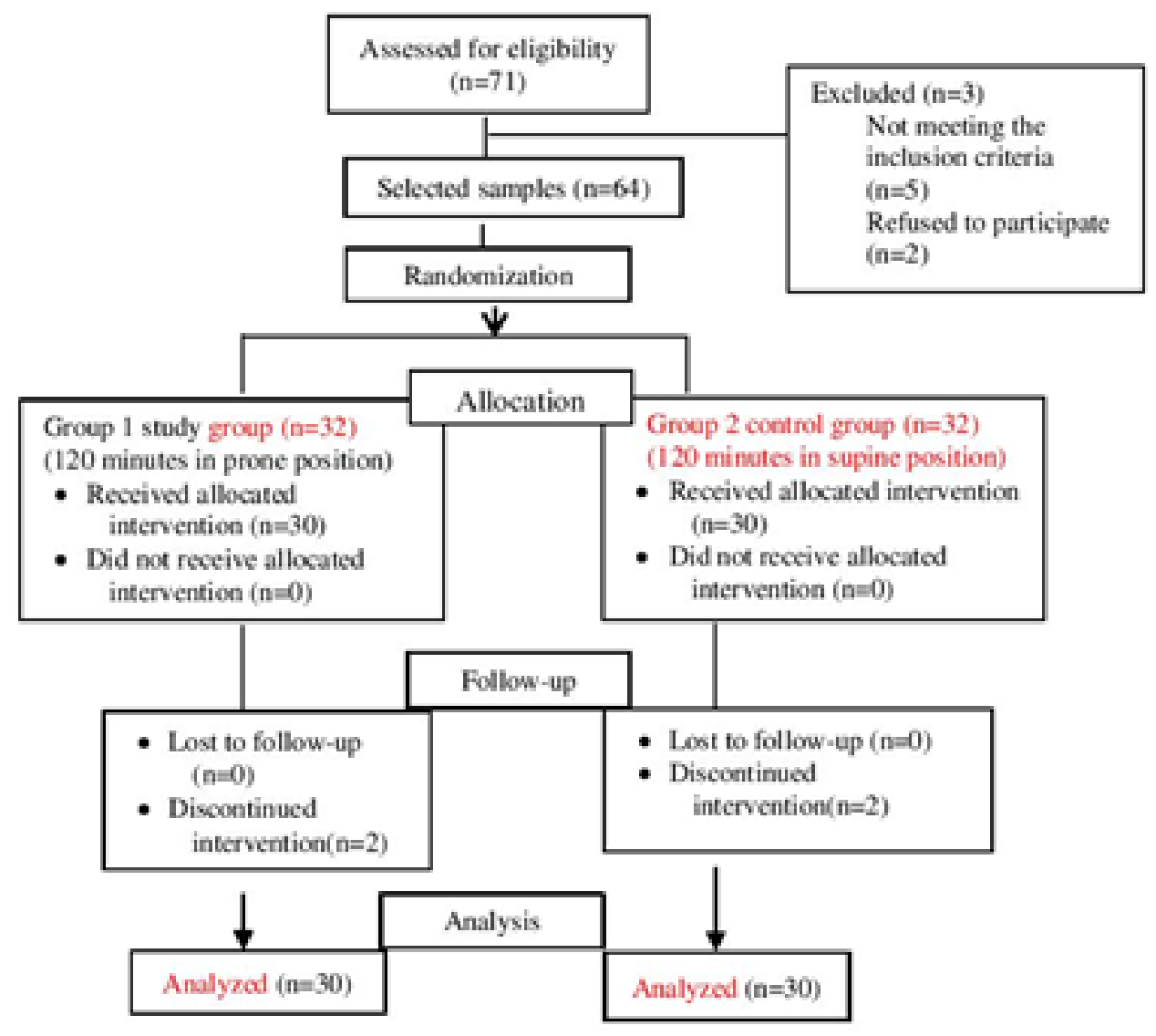

Figure 1 CONSORT flow diagram of participant recruitment process 
currently on CPAP; 3 ) currently undergoing CPAP weaning with gradual decreased oxygen fraction automatically $(\mathrm{FiO} 2<25 \%)$; 4) had no contraindication for prone and supine position (e.g., post-abdominal surgery, congenital heart disease). The exclusion criteria included infants who had severe congenital diseases Tetralogy of Fallot (ToF) and diaphragmatic hernia), worsening oxygenation status or hemodynamically unstable, had a history of air leak syndrome and lung collapse, and infants with mottle. Based on the study by Antunes et al. (2003) obtained the proportion of failure incidence in P1 (failure wean in prone position) of $4 \%$ and $33 \%$ of success in P2 (success wean in supine position), so the number of respondents per group was 30 respondents. The sample size calculation was based on the hypothesis test formula with different proportions of the independent group (Dahlan, 2016).

$\mathrm{Z} \alpha=1.96 ; \quad \alpha=0.05, \quad \mathrm{~B}=0.20 ; \mathrm{P} 1=0.04$; $\mathrm{P} 2=0.33 ; \quad \mathrm{P} 1-\mathrm{P} 2=0.29$ (effect size); $\mathrm{P}$ $=(1 / 2(\mathrm{P} 1+\mathrm{P} 2))$

$$
\mathrm{n}=\frac{\left\{z_{1-a / 2} \sqrt{2 \overline{\mathrm{P}}(1-\overline{\mathrm{P}})}+z_{1-\rho} \sqrt{\mathrm{P}_{1}\left(1-\mathrm{P}_{1}\right)+\mathrm{P}_{2}\left(1-\mathrm{P}_{2}\right)}\right\}^{2}}{\left(\mathrm{P}_{1}-\mathrm{P}_{2}\right)^{2}}
$$

The Health Research Ethics Committee at the National Hospital Cipto Mangunkusumo approved this study with a requirement to obtain written consent from the participants at Rumah Sakit Umum Pusat Fatmawati and Rumah Sakit Pusat Angkatan Darat Gatot Subroto (Reff: 279/UN2.F1/ETIK/ PPM.00.02/2020).

\section{Intervention}

Each infant have different time for readiness weaning from CPAP. The study process takes place from 08.00 a.m.- 04.00 p.m. For each study group, the intervention was conducted twice a day one infant in control group and one infant in study group which lasted for 150 minute. The authors have previously shared the aim and explained the procedures of the study to the NICU nurses who cared for the infants recruited for the study. The procedures of the study were based on a previous study by Babaei, Mohammadi, and Soleimani (2019), the authors made observations every 15 minute for 120 minute. Due to the possibility of the instability of the physiological conditions, in the first 15 minutes of placing the infant in any of the two positions, no data was recorded; then, after the infant was in constant conditions, every 15 minutes, heart rate, $\mathrm{SpO} 2$, and respiratory rate were recorded.

\section{a. Prone position}

The infant in study group were turned to a prone position for 120 minute, and level of heart rate, respiratory rate, oxygen saturation were recorded every 15 minute. The intervention procedure followed a protocol developed based on Efendi, Sari, Riyantini, Anggur, and Lestari (2019) which was follows: a) The author prepared a tool, a swaddling cloth to support the baby's body when giving position, $b$ ) Preparing assessment and observation sheets, and ensuring the readiness of the monitor to function properly, c) Ensuring that the positioning was done after 60 minutes feeding competed d) Nurses washed their hands according to WHO guidelines, e) Nurses provide prone positions with several stages, namely: 1) Maintaining the baby's head in the midline or midline position and not turning to one side, and providing soft pads on the baby's neck to support the head, 2 ) Give the head a slightly flexed position with the chin close to the chest, 3) Give the baby a soft cloth until the shoulders are slightly flexed towards the chest, 4) The position of the baby's hands is abducted so that the ends of the hands are near the baby's mouth, 5) Then give the position of the hips and knees flexion, 6) The baby's knees are in the midline of body growth and the position of the knees is not wide open, 7) Provide a nest position to be able to support 
the legs in a flexed and crossed position, 8) tighten the nest on the outermost part of the baby's body so that it looks like the baby is confined in a cage and attaches the fixation to the nesting see Fig 2.

\section{b. Supine position}

The infant in control group were placed to a supine position for 120 minute, and level of heart rate, respiratory rate, oxygen saturation were recorded every 15 minute. Whereas the supine position is given through several stages, namely: 1) Maintaining the baby's head in the midline or midline position and not turning to one side, and providing soft pads on the baby's neck to support the head, 2) Providing a slightly flexed head position with the chin close to the chest, 3) Give a soft cloth to the baby until the shoulders are slightly flexed towards the chest, 4) The position of the baby's hands is abducted so that the ends of the hands are near the baby's mouth, 5) Then give the position of the hips and knees flexed, 6) The baby's knees are in the middle line of growth body and knee positions are not wide open, 7) Provide a nest position to support the legs to form a flexed and crossed position, 8) Tighten the nest on the outer part of the baby's body so that it looks like the baby is confined in a cage and attaches the fixation to nesting see Fig. 2.

The measurements in this study were parameters of oxygenation status were namely oxygen saturation, respiratory rate, and heart rate. As references, normal values of vital signs for preterm infants are follows: heart rate of $121-179$ beats per minute; respiratory rate of 21 - 59 breaths per minute; and oxygen saturation ( $\mathrm{SpO} 2)$ of $\geq 93 \%$ (Baker, 2015). The data collection tools used were the observation sheet to obtain primary data directly from the respondent's parents and medical records. Measurement of oxygenation status using a cardiorespiratory
(A)

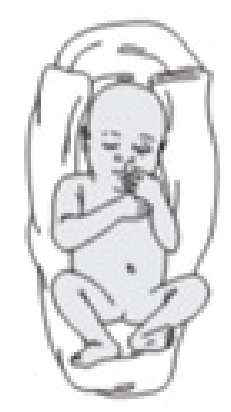

(B)

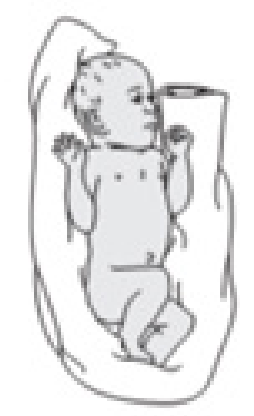

(A)

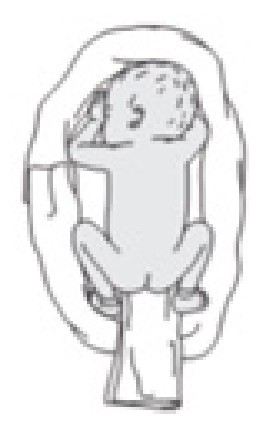

(B)

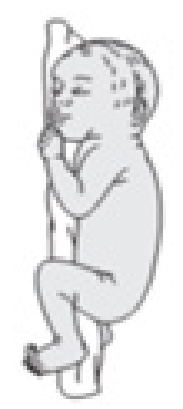

Prone position $\mathrm{A}$ and $\mathrm{B}$

Figure 2 The illustration of giving body position for preterrm infants (Source: Boxwel (2010): Neonatal Intensive Care Nursing. 2nd Edition) 
monitor, pulse oximetry to assess oxygen saturation that has been calibrated at the hospital's electromedical technician, and to support the positioning of the baby's body using a soft swaddle.

Data collection

The measurement is divided into 3 parts, namely; 1) baseline data for 10 seconds, the author recorded the oxygenation status before giving the position (T0); 2) the resting phase, namely the author and NICU nurses provides a prone/supine body position for 15 minutes to prevent the effects of previous activities or positioning; 3) the intervention phase of the baby in the prone/supine position for 120 minutes (T1-T7), see Fig.1 (Babaei, Mohammadi, \& Soleimani, 2019).

Infants who experienced an increase in respiratory rate of $>75$ times/minute, desaturation of $<88 \%$, and bradycardia $(<100$ beats/min)for less than 6 hours were considered CPAP failure, and thus, needed to be back on CPAP (re-CPAP) (Wright, Sherlock, Sahni, \& Polin, 2018).
Demographics and clinical history were collected from the patient's medical records, including the use of surfactants, antenatal steroids, intrauterine growth restriction (IUGR), patent ductus arteriosus (PDA), bronchopulmonary dysplasia (BPD), and gastroesophageal reflux. The duration of use of CPAP has been recorded from the time the infant received various forms of the noninvasive ventilator (Bubble Continuous Positive Airway Pressure (BCPAP) or non invasive ventilator (NIV).

Data analysis

Normality test on data oxygen saturation, respiratory rate, and heart rate at start intervention 30 minutes (T1) and end of intervention at 120 minutes (T7) with the Shapiro Wilk test. While the homogeneity test on demographic data used the Independent T-test. Bivariate analysis between physiological parameter and body position was applied by used the Independent t-test. In addition, the corellation between re-CPAP and body position were used Chisquare $(\alpha=0.05)$.

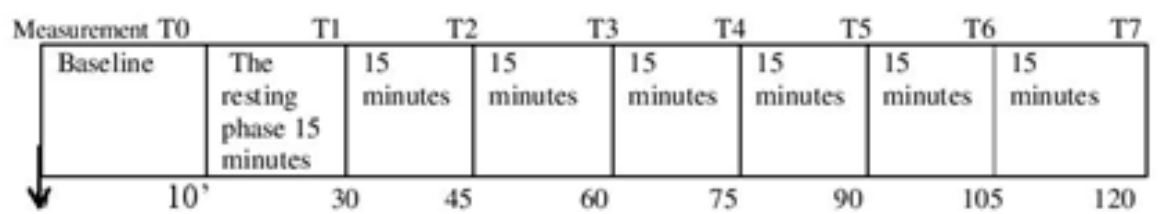

Figure 3 The sequence of study procedure

\section{Results}

\section{Subjects' Demography}

The characteristics of the infants who participated in this study were the mean gestational age of premature babies in the prone position with RDS 32.87 weeks, while the mean age of correction was 33.90 weeks. The average length of time using CPAP in the prone position was faster than the supine position, which was 6.3 days. Based on the results of the homogeneity test, it can be seen that there is no difference in the characteristics of the intervention group and the control group ( $\mathrm{p}$ value $>0.05$ ) (Table $1)$. The proportion of males was $66.7 \%$, and preterm infants who failed weaning were 9 respondents (15\%) (Table 1). However, the bivariate analysis were used chi-square results between body position against reCPAP were not significant. See table 2. Based on table 3 preterm infants who failed to wean off CPAP, the mean age of gestation was 30 weeks, birth weight was 1440 grams, and the duration of using CPAP was 12.3 days. Based on table 4 , the preterm infants who failed to wean off CPAP (reCPAP) did not get antenatal steroids 8 infants, not getting surfactant 7 infants, and experiencing sepsis/NEC 7 infants.

\section{Oxygen saturation}

The intervention was conducted in 120 
minute, from the baseline (T0) until end of intervention (T7) the mean of oxygen saturation of prone position more higher than supine position (see table 5). Independent T-test showed that there was a difference in the percentage oxygen saturation between the prone and supine groups at 30 minutes (T1) and 120 minutes (T7). At 30 minutes (T1), the mean percentage oxygen saturation was significantly higher in infants with prone position $(99.87 \pm 0.35)$ compared with that in infants with supine position $(97.63 \pm 1.45$; $\mathrm{p}=0.001)$. Similarly, the mean percentage oxygen saturation was also higher in infants with prone position compared with that in infants with supine position at 120 minutes $(100 \pm 0.00$ vs $97 \pm 0.87 ; p=0.001)$, see table 5.

\section{Respiration rates}

The mean of preterm infant's respiration rate in the prone group was lower than in the supine group, and more stable at T5 (see table 5). Further analysis with the Independent

Table 1 Demographic Characteristics of Preterm Infants May - September $2020(n=60)$

\begin{tabular}{|c|c|c|c|c|c|c|c|c|c|}
\hline \multirow{2}{*}{ Characteristic } & \multicolumn{4}{|c|}{ Prone } & \multicolumn{4}{|c|}{ Supine } & \multirow[b]{2}{*}{$\mathbf{P}$} \\
\hline & $(\mathrm{n}, \%)$ & Mean & SD & $\begin{array}{l}\text { Min- } \\
\text { Max }\end{array}$ & $(n, \%)$ & Mean & SD & $\begin{array}{l}\text { Min- } \\
\text { Max }\end{array}$ & \\
\hline $\begin{array}{l}\text { Gestational age } \\
\text { (week)* }\end{array}$ & & 32.87 & 2.57 & $28-36$ & & 32.07 & 3.34 & $26-36$ & 0.303 \\
\hline $\begin{array}{l}\text { Correctional age } \\
\text { (week)* }\end{array}$ & & 33.90 & 2.52 & $29-38$ & & 32.43 & 3.42 & $26-36$ & 0.064 \\
\hline $\begin{array}{l}\text { Actual body } \\
\text { weight (gram)* }\end{array}$ & & 1873 & 439.05 & $\begin{array}{l}1165- \\
2670\end{array}$ & & 1657.33 & 566.27 & $\begin{array}{l}800- \\
3200\end{array}$ & 0.309 \\
\hline $\begin{array}{l}\text { Prolong of using } \\
\text { CPAP (day)* }\end{array}$ & & 6.30 & 2.63 & $2-14$ & & 9.33 & 3.42 & $3-15$ & 0.062 \\
\hline \multicolumn{10}{|l|}{ Sex** } \\
\hline Male & $21(52.5)$ & & & & $19(47.5)$ & & & & 0.784 \\
\hline Female & $9(45)$ & & & & $11(55)$ & & & & \\
\hline $\begin{array}{l}\text { Antenatal } \\
\text { steroids** }\end{array}$ & $9(15)$ & & & & 11(18.3) & & & & 0.791 \\
\hline Surfactant** & $2(3.3)$ & & & & $3(5)$ & & & & 0.647 \\
\hline Sepsis/NEC $* *$ & $9(15)$ & & & & $11(18.3)$ & & & & 0.584 \\
\hline PDA** & 13(21.7) & & & & $16(26.5)$ & & & & 0.438 \\
\hline IUGR** & $9(15)$ & & & & $15(25)$ & & & & 0.114 \\
\hline \multicolumn{10}{|l|}{ Re-CPAP** } \\
\hline Yes & $3(5)$ & & & & $6(10)$ & & & & \\
\hline No & $27(45)$ & & & & $24(40)$ & & & & \\
\hline
\end{tabular}

ॠIndependent t-test,

**Chi-square; Abbreviations: NEC: enterocolitis necroticans,

**PDA: patent ductus arteriosus, IUGR: intrauterine growth restriction. 
Ayu Simorangkir: Prone Position Improve Physiological Parameters of Preterm Infants Weaning from CPAP

Table 2 The Relation Between Recpap with Prone and Supine Position (N=60)

\begin{tabular}{|c|c|c|c|c|c|c|c|c|}
\hline \multirow{3}{*}{ Intervention groups } & \multicolumn{6}{|c|}{ reCPAP } & \multirow{3}{*}{ Correlation } & \multirow{3}{*}{ p-value } \\
\hline & \multicolumn{2}{|c|}{ no } & \multicolumn{2}{|c|}{ yes } & \multicolumn{2}{|c|}{ Total } & & \\
\hline & n & $\%$ & $\mathbf{n}$ & $\%$ & $\mathbf{n}$ & $\%$ & & \\
\hline Prone & 27 & 90 & 3 & 10 & 30 & 100 & 0.140 & 0.472 \\
\hline Supine & 24 & 80 & 6 & 20 & 30 & 100 & & \\
\hline Total & 51 & 85 & 9 & 15 & 60 & 100 & & \\
\hline
\end{tabular}

*Chi square

Table 3 Demographic Characteristics of The Preterm Infant with Recpap (Gestational Age, Birth Weight, Duration of Using Cpap) $(\mathrm{N}=9)$

\begin{tabular}{lcc}
\hline \multicolumn{1}{c}{ Characteristic } & Mean & Min-Max \\
\hline Gestational age (weeks) & 30 & $27-32$ \\
Birth weight (grams) & 1440.3 & $800-2100$ \\
Duration of using CPAP (days) & 12.3 & $7-15$ \\
\hline
\end{tabular}

Table 4 Demographic Characteristics of The Preterm Infant with Recpap (Antenatal Steroids, Surfactant, Sepsis/Nec, Pda, Iugr) $(\mathrm{N}=9)$

\begin{tabular}{lcc}
\hline \multicolumn{1}{c}{ Characteristic } & Yes & No \\
\hline Antenatal steroids & 1 & 8 \\
Surfactant & 2 & 7 \\
Sepsis/NEC & 7 & 2 \\
PDA & 3 & 6 \\
IUGR & 4 & 5 \\
\hline
\end{tabular}

Table 5 The Mean of Oxygen Saturation, Respiration Rate and Heart Rate In Prone and Supine Position During Intervention

\begin{tabular}{lccccc}
\hline \multirow{2}{*}{ Category } & Time & \multicolumn{2}{c}{ Prone } & \multicolumn{2}{c}{ Supine } \\
\cline { 3 - 6 } & & mean & SD & mean & SD \\
\hline $\begin{array}{l}\text { Oxygen } \\
\text { Saturation }\end{array}$ & T0 & 97.87 & 1.19 & 97.00 & 1.43 \\
& T1 & 99.87 & 0.35 & 97.63 & 1.45 \\
& T2 & 99.23 & 1.00 & 97.50 & 1.50 \\
& T3 & 99.60 & 0.62 & 97.47 & 1.50 \\
\hline
\end{tabular}


Ayu Simorangkir: Prone Position Improve Physiological Parameters of Preterm Infants Weaning from CPAP

\begin{tabular}{|c|c|c|c|c|c|}
\hline \multirow{2}{*}{ Category } & \multirow{2}{*}{ Time } & \multicolumn{2}{|c|}{ Prone } & \multicolumn{2}{|c|}{ Supine } \\
\hline & & mean & SD & mean & SD \\
\hline \multirow{4}{*}{$\begin{array}{l}\text { Oxygen } \\
\text { Saturation }\end{array}$} & $\mathrm{T} 4$ & 99.97 & 0.18 & 97.13 & 1.38 \\
\hline & $\mathrm{T} 5$ & 100 & 0 & 97.23 & 1.50 \\
\hline & T6 & 100 & 0 & 97.13 & 1.22 \\
\hline & $\mathrm{T} 7$ & 100 & 0 & 97.00 & 0.87 \\
\hline \multirow[t]{8}{*}{ Respiration Rate } & T0 & 49.03 & 6.32 & 53.30 & 7.16 \\
\hline & $\mathrm{T} 1$ & 42.10 & 8.59 & 53.20 & 6.24 \\
\hline & $\mathrm{T} 2$ & 41.73 & 5.06 & 52.53 & 7.50 \\
\hline & $\mathrm{T} 3$ & 38.57 & 6.17 & 54.17 & 7.00 \\
\hline & $\mathrm{T} 4$ & 37.83 & 5.66 & 52.70 & 6.96 \\
\hline & T5 & 36.27 & 5.77 & 53.63 & 6.87 \\
\hline & T6 & 36.13 & 4.66 & 54.47 & 6.65 \\
\hline & $\mathrm{T} 7$ & 34.37 & 4.66 & 56.47 & 4.49 \\
\hline \multirow[t]{8}{*}{ Heart Rate } & T0 & 155.83 & 7.28 & 154.80 & 9.03 \\
\hline & $\mathrm{T} 1$ & 144.63 & 13.07 & 153.53 & 10.02 \\
\hline & $\mathrm{T} 2$ & 143.30 & 10.36 & 153.40 & 8.73 \\
\hline & $\mathrm{T} 3$ & 141.57 & 8.06 & 153.77 & 8.46 \\
\hline & $\mathrm{T} 4$ & 138.93 & 6.51 & 153.90 & 7.84 \\
\hline & T5 & 138.57 & 6.71 & 153.00 & 8.69 \\
\hline & T6 & 137.07 & 5.61 & 155.53 & 8.38 \\
\hline & $\mathrm{T} 7$ & 135.73 & 4.14 & 158.30 & 8.50 \\
\hline
\end{tabular}

Table 6 Differences In Oxygen Saturation, Respiratory Rate, and Heart Rate Between Two Groups $(\mathbf{N}=6)$

\begin{tabular}{lcccc}
\hline \multicolumn{1}{c}{ Physiological Parameters } & \multicolumn{2}{c}{ Intervention groups } & \multicolumn{2}{c}{ T Independent } \\
\cline { 2 - 5 } & Prone & Supine & T value & P-value \\
\hline Oxygen saturation & & & & \\
Baseline 0 minute (T0) & $97.87+1.19$ & $97.00+1.43$ & 2.488 & 0.628 \\
30 minutes (T1) & $99.87+0.35$ & $97.63+1.45$ & 8.206 & 0.001 \\
120 minutes (T7) & $100+0.00$ & $97+0.87$ & 18.866 & 0.001 \\
\hline
\end{tabular}




\begin{tabular}{|c|c|c|c|c|}
\hline \multirow[t]{2}{*}{ Physiological Parameters } & \multicolumn{2}{|c|}{ Intervention groups } & \multicolumn{2}{|c|}{ T Independent } \\
\hline & Prone & Supine & T value & P-value \\
\hline \multicolumn{5}{|l|}{ Respiratory rate } \\
\hline Baseline 0 menit (T0) & $49.03+6.32$ & $53.30+7.16$ & 2.538 & 0.318 \\
\hline 30 minutes (T1) & $42.10+8.59$ & $53.20+6.24$ & 5.726 & 0.001 \\
\hline 120 minutes (T7) & $34.37+4.66$ & $56.47+4.49$ & 18.705 & 0.001 \\
\hline \multicolumn{5}{|l|}{ Heart rate } \\
\hline Baseline 0 menit (T0) & $155.83+7.28$ & $154,80+9.03$ & 2.446 & 0.471 \\
\hline 30 minutes (T1) & $144.63+13.07$ & $153,53+10.02$ & 2.959 & 0.004 \\
\hline 120 minutes (T7) & $135.73+4.13$ & $158,30+8.50$ & 13.074 & 0.001 \\
\hline
\end{tabular}

T-test showed that the respiratory rate of the groups in the prone and supine positions at 30 minutes (T1) and at 120 minutes (T7) obtained $\mathrm{p}$-value $=0.001<\alpha(0.05)$, it can be explained that there was a difference. significantly the respiratory rate at 30 minutes (T1) and 120 minutes (T7) between the prone and supine position groups (see table 5).

Heart rates

The mean of heart rate in the prone group was lower than that in the supine group (see table 5). The results of further analysis with the Independent T-test showed that the heart rate of the group prone and supine positions at 30 minutes (T1) obtained $\mathrm{p}$-value $=0.004$ $<\alpha(0.05)$ and at 120 minutes (T7) obtained p-value $=0.001<\alpha(0.05)$ it can be explained that there was a significant difference in heart rate at 30 minutes (T1) and 120 minutes (T7) between the prone and supine position groups (see table 5).

\section{Discussion}

Theresultsshowed thatchangesinoxygenation status were seen in the first 30 minutes. The change in oxygenation status started from 30 minutes and stable at 120 minutes $(100 \%)$, post-administration and the mean oxygen saturation at the prone position tended to be stable and save while compared to the supine position. Abdeyazdan, Nematollahi, Ghazavi, and Mohhamadizadeh (2010) stated preterm infant with undergoing from mechanical ventilation the change in oxygen saturation was significant after the first 15 minutes to 120 minutes after administration $(p=0.01)$. The main results of this study indicated that there was a significant difference between the position of the prone and supine bodies on oxygen saturation, respiratory rate, and heart rate $(\mathrm{p}=0.001)($ Table 5$)$.

The prone position has a positive impact on oxygen saturation, namely reaching the normal range ( $>93 \%-100 \%)$ after 90 minutes post positioning. The results showed that there was a significant difference after giving the prone position for 120 minutes undergoing CPAP weaning $(\mathrm{p}=0.001)$. In the study by Babaei et al. (2019) giving the prone position for 180 minutes to 62 infants with NCPAP, the mean oxygen saturation in the prone position was higher and stable than the supine position $(\mathrm{p}=<0.001)$. This is because the prone position provides better synchronization between the thorax and abdomen, resulting in increased tidal volume and a better oxygen saturation impact (Malagoli et al., 2012).

During the observation of 120 minutes, the mean heart rate was stable at $\mathrm{T} 4$ and T5, namely 75-90 minutes after giving the position. Ghorbani, Asadollahi, and Valizadeh (2013) identified that giving the prone and supine positions to 2 groups for 120 minutes in preterm infants with NCPAP-attached respiratory distress showed a change in heart rate in the first group of prone positions, 
namely $135 \pm 15.04$ beats per minute and the supine group $144.27 \pm 130.9$ beats per minute $(p=0.002)$. In the supine position, the heart rate during observation tended to be tachycardia with the average heart rate in 120 minutes, namely $158.30+8.50$. The results of a study by Hough et al. (2016) involving 60 preterm infants identified the impact of giving a prone position in premature infants with CPAP, there was an increase in lung muscle in the first 2 hours (0.02) and stable for the first 4 hours $(p=0.03)$, the heart rate was more stable in the prone position. This could be due to the prone position providing better synchronization between the thorax and abdomen, thus making the diaphragm muscle shorten better (Malagoli et al., 2012). Good coordination between the thorax and abdomen helps premature babies to adapt better in improving the muscle for breathing.

The results of the observation of the respiratory rate showed that the prone position group experienced changes in the normal range for each time change $(p=0.001)$. This is supported by the study of Ghorbani et al. (2013) who stated that there was a change in the mean respiratory rate in preterm infants with respiratory distress attached to NCPAP during the 120-minute prone position, where the tachypnea was initially more stable $(\mathrm{p}=$ 0.002 ). In line with the study of Babaei et al. (2019) giving the prone position for 180 minutes to 62 infants with NCPAP, the mean respiratory rate was better at $55.61 \pm 6.4(\mathrm{p}=$ $<0.001)$.

The weaning success of CPAP at the prone position compared to the supine position is not significant. Respondents who experienced reCPAP in the supine group were 6 respondents. The results of the further analysis showed no relationship between assignment and reCPAP. The author has not found any literature on assigning a position to prevent reCPAP. However, giving prone body position from several study results can provide a positive impact for premature babies with respiratory distress, namely better stability of oxygen saturation, respiratory rate, and heart rate.

Several factors that influence the success of weaning CPAP are gestational age, age of correction, and birth weight (AbdelHady et al., 2015). Meanwhile, factors that can delay the wean off CPAP are maternal chorioamnionitis, anemia, infants experiencing gastroesophageal reflux which can prolong the duration of CPAP used (Rastogi et al., 2012). In this study, infants who experienced reCPAP were 27-32 weeks' gestation, birth weight. 800-2100 grams and experiencing sepsis / NEC. Preterm infants experienced failed to wean off CPAP with the length of CPAP used were 7-15 days. According to a study by Rastogi et al. (2012), birth weight, chorioamnionitis, anemia, and GER played a significant role in weaned off CPAP and the length of CPAP use. Wright, Sherlock, Sahni, and Polin, (2018) babies with a gestation age of 25-28 weeks tend to fail to wean off CPAP (45\%), among them have low birth weight and born with cesarean section. So that action was needed to prevent dependence on a long breathing device and the occurrence of bronchopulmonary dysplasia (BPD). Dargaville et al. (2013) stated that antenatal use of corticosteroids in mothers who are threatened with giving birth at 24-33 weeks' gestation can reduce re-CPAP $(>90 \%)$.

Limitation

The limitation of the study was the author did not investigate any differences in the use of the CPAP setting in the two hospitals, namely the use of BCPAP and CPAP that use ventilator mode (NIV). Furthermore, the study should use the position of quarter prone or semi-prone. Addittion, the author was not compare the demographics with physiological parameters between 2 groups that might be effect of weaning process.

\section{Conclusion}

Oxygen saturation in infants in prone position tends to be more stable than infants in the supine position. The respiratory rate and heart rate were also more stable in the prone than in the supine position group. There were significant differences in oxygen saturation, respiratory rate, and heart rate at 30 minutes (T1) and 120 minutes (T7) between the prone and supine position groups. Infants from the supine group had more reCPAP were 6 infants. There is no relationship between assignment 
and reCPAP. Positioning is a strategy for treating premature infants and has a positive impact on both neuromotor, musculoskeletal and physiological functions. So that the nurse can give positioning especially prone position saved about 120 minute. In addition, It is very important to created stability of the infant's oxygenation status during the CPAP weaning process. Nurses can better apply and documented monitor the positioning of preterm infants undergoing the CPAP weaning process.

\section{Acknowledgment}

Thanks to the pediatric nurses in the NICU room at Fatmawati Hospital and Gatot Subroto Army Hospital who were involved in the study. Thanks were also extended to all mothers of premature infants who were willing to become respondents.

\section{References}

Abdel-Hady, H., Shouman, B., \& Nasef, N. (2015). Weaning preterm infants from continuous positive airway pressure: evidence for best practice. World Journal of Pediatrics, 11(3), 212-218. https://doi. org/10.1007/s12519-015-0022-6.1

Abdeyazdan, Z., Nematollahi, M., Ghazavi, Z., \& Mohhamadizadeh, M. (2010). The effects of supine and prone positions on oxygenation in premature infants undergoing mechanical ventilation. Iranian Journal of Nursing and Midwifery Research, 15(4), 229-233. Retrieved December 23, 2020, from http://www.ncbi.nlm.nih.gov/ pubmed/22049286\%0A

Amatya, Shaili, Rastogi, D., Bhutada, A., \& Rastogi, S. (2014). Weaning of nasal CPAP in preterm infants: Who, when and how? A systematic review of the literature. World Journal of Pediatric, 11(1):7-13. https://doi. org/10.1007/s12519-014-0535-4

Babaei, H., Mohammadi Pirkashani, L., \& Soleimani, B. (2019). omparison of the effect of supine and prone positions on physiological parameters of preterm infants under nasal continuous positive airway pressure (N-CPAP): A cross over clinical trial. Cukurova Medical Journal, 44(4), 1250 1255. https://doi.org/10.17826/cumj.512192

Baker, B. (2015). Evidence-based practice to improve outcomes for late preterm infants. Journal of Obstetric, Gynecologic, and Neonatal Nursing, 44(1), 127-134. https:// doi.org/10.1111/1552-6909.12533

Boxwell, G. (2010). Neonatal intensive care nursing 2nd ed. Routledge.

Chawla, S., Natarajan, G., Shankaran, S., Carper, B., Gantz, M. G., Das, A., Ronald, N. (2017). Markers of successful extubation in extremely preterm infants, and morbidity after failed extubation. HHS Public Access. US: Hospitals of Leicester. https://doi.org/10.1016/j.jpeds.2017.04.050

Committee on Fetus and Newborn. (2014). Respiratory support in preterm infants at birth. Pediatrics, 133(1), 171-174. https:// doi.org/10.1542/peds.2013-3442

Dahlan, M.S. (2016). Besar sampel dalam penelitian kedokteran dan kesehatan, seri 2 (Edisi 4). Epidemiologi Indonesia.

Dargaville, P. A., Aiyappan, A., De Paoli, A. G., Dalton, R. G. B., Kuschel, C. A., Kamlin, C. O., Davis, P. G. (2013). Continuous positive airway pressure failure in preterm infants: Incidence, predictors and consequences. Neonatology, 104(1), 8-14. https://doi.org/10.1159/000346460

Dunn, M.S., Kaempf, J., de Klerk A, de Klerk R, Reilly M., Howard D., Ferrelli K., O'Conor J, Soll R.F., Vermont Oxford Network DRM Study Group. (2011). Randomized trial comparing 3 approaches to the initial respiratory management of preterm neonates. Pediatrics, 128(5):e1069-e1076. https://doi. org/10.1542/peds.2010-3848

Efendi, D., Sari, D., Riyantini, Y., Anggur, D., \& Lestari, P. (2019). Pemberian posisi (positioning) dan nesting pada bayi prematur : evaluasi implementasi perawatan di neonatal intensive care unit (NICU). JKI, 22(3),169- 
Ayu Simorangkir: Prone Position Improve Physiological Parameters of Preterm Infants Weaning from CPAP

\section{1. https://doi.org/10.7454/jki.v22i3.619}

Emaliyawati, E., Fatimah, S., \& Lidya, L. (2018). Pengaruh Terapi Musik Lullaby terhadap Heart Rate, Respiration Rate, Saturasi Oksigen pada Bayi Prematur. Jurnal Keperawatan Padjadjaran, 5(3). https://doi. org/10.24198/jkp.v5i3.648

Ghorbani, F., Asadollahi, M., \& Valizadeh, S. (2013). Comparison the effect of sleep positioning on cardiorespiratory rate in noninvasive ventilated premature infants. Nursing and Midwifery Studies, 1(4), 182187. https://doi.org/10.5812/nms. 10318

Güler, F. \& Çalışır, H. (2020). The effect of positioning on adaptation to spontaneous breathing in premature infants after weaning from mechanical ventilation: a randomized controlled trial. The Journal of Pediatric Research, 7(2),102-109. https://doi. org/10.4274/jpr.galenos.2019.19042

Hendrawati, S., Fatimah, S., Fitri, R., Nurhidayah, I. (2017). Kajian Kebutuhan Family Centered Care dalam Perawatan Bayi Sakit Kritis di Neonatal Intensive Care Unit. Jurnal Keperawatan Padjadjaran, 5(2). https://doi.org/10.24198/jkp.v5i2.453

Ho, J.J., Subramaniam, P, Davis, P.G. (2020). Continuous positive airway pressure (CPAP) for respiratory distress in preterm infants. Cochrane Database Systematic Review,(10), 1-40. https://doi.org/10.1002/14651858. CD002271

Hough, J., Trojman, A., \& Schibler, A. (2016). Effect of time and body position on ventilation in premature infants. Pediatric Research, 80(4), 499-504. https://doi. org/10.1038/pr.2016.116

Lam, R., Schilling, D., Scottoline, B., Platteau, A., Niederhausen, M., Lund, K. C., McEvoy, C. T. (2019). The effect of extended continuous positive airway pressure on changes in lung volumes in stable premature infants: A randomized controlled trial. The Journal of Pediatrics, 1-8. https://doi. org/10.1016/j.jpeds.2019.07.074

Maffei, G., Gorgoglione, S., \& Vento, G. (2017). Noninvasive ventilation: Systematic approach and new perspectives for preterm infants. Journal of Clinical Neonatology, 6(3), 135. https://doi.org/10.4103/jen.jen_121_16

Malagoli, R.C., Fagundes, F., Santos, A., Oliveira, E. A., Cândida, M., \& Bouzada, F. (2012). Influence of prone position on oxigenation, respiratory rate and muscle strength in preterm infants being weaned from mechanical ventilation. Rev Paul Pediatr, 30(22), 251-6251. https://doi.org/10.1590/ S0103-05822012000200015

Montgomery, K., Choy, N. L., Steele, M., \& Hough, J. (2014). The effectiveness of quarter turn from prone in maintaining respiratory function in premature infants. Journal of Paediatrics and Child Health, 50(12), 972977. https://doi.org/10.1111/jpc.12689

Rastogi, S., Rajasekhar, H., Gupta, A., Bhutada, A., Rastogi, D., \& Wung, J.-T. (2012). Factors affecting the weaning from nasal CPAP in preterm neonates. International Journal of Pediatrics, 12(1), 1-7. https://doi. org/10.1155/2012/416073

Torabian, H., Alinejad, S., Bayati, A., Rafiei, F., \& Khosravi, S. (2019). Comparison of the effects of supine and prone positions on oxygen saturation and vital signs in premature infants: A crossover clinical trial. Iranian Journal of Neonatology, 10(2), 30-36. https:// doi.org/10.22038/ijn.2019.32928.1465

Wright, C. J., Sherlock, L., Sahni, R., \& Polin, R. A. (2018). Preventing CPAP failure: Evidence-Based and physiologically sound practices from delivery room to the NICU. Clinical Perinatology, 176(1), 139-148. https://doi.org/10.1016/j.clp.2018.01.011 